\title{
Evaluation of High-Resolution Satellite-Based Real-Time and Post-Real-Time Precipitation Estimates during 2010 Extreme Flood Event in Swat River Basin, Hindukush Region
}

\author{
Muhammad Naveed Anjum,,2,3 Yongjian Ding, 1,2 Donghui Shangguan," \\ Muhammad Wajid Ijaz, ${ }^{4}$ and Shiqiang Zhang ${ }^{5}$

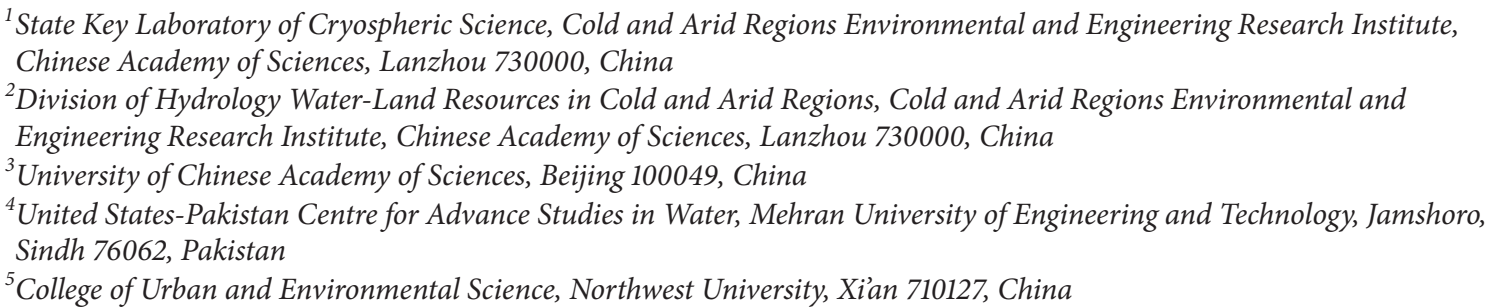

Correspondence should be addressed to Muhammad Naveed Anjum; naveedwre@lzb.ac.cn

Received 14 December 2015; Revised 20 February 2016; Accepted 24 February 2016

Academic Editor: Tomoo Ushio

Copyright (c) 2016 Muhammad Naveed Anjum et al. This is an open access article distributed under the Creative Commons Attribution License, which permits unrestricted use, distribution, and reproduction in any medium, provided the original work is properly cited.

\begin{abstract}
Satellite-based real-time and post-real-time precipitation estimates of Tropical Rainfall Measuring Mission (TRMM) Multisatellite Precipitation Analysis (TMPA-3B42) were evaluated during an extreme heavy precipitation event (on 28-30 July 2010) over Swat River Basin and adjacent areas in Hindukush Region. Observations of 15 rain gauging stations were used for the evaluation of TMPA products. Results showed that the spatial pattern of precipitation in the event was generally captured by post-real-time product (3B42V7) but misplaced by real-time product (3B42RT), witnessed by a high spatial correlation coefficient for 3B42V7 $(C C=0.87)$ and low spatial correlation coefficient for 3B42RT $(C C=0.20)$. The temporal variation of the storm precipitation was not well captured by both TMPA products. 3B42V7 product underestimated the storm accumulated precipitation by $32.15 \%$, while underestimation by $3 \mathrm{~B} 42 \mathrm{RT}$ was $66.73 \%$. Based on the findings of this study, we suggest that the latest TMPA-based precipitation products, 3B42RT and 3B42V7, might not be able to perform well during extreme precipitation events, particularly in complex terrain regions like Hindukush Mountains. Therefore, cautions should be considered while using 3B42RT and 3B42V7 as input data source for the modelling, forecasting, and monitoring of floods and potential landslides in Hindukush Region.
\end{abstract}

\section{Introduction}

Extreme precipitation events are very common in Pakistan. The monsoon currents developed on 24 July 2010, in the Bay of Bengal, and reached the northwestern region of Pakistan on the 27th of July 2010, which caused unprecedented precipitation event. This unprecedented intense event brought the worst flooding of the last 80 years in the region [1]. The storm caused 2,000 deaths and a cumulative direct economic loss of US\$ 10 billion. 17,553 villages were destroyed/damaged, and an overall $20 \%$ area $\left(160,000 \mathrm{~km}^{2}\right)$ of the country was inundated. It is a matter of immense interest for the benefit of the region to monitor the extreme precipitation events that led to the severe floods and landslides [2-4].

Acquiring accurate precipitation estimates is one of the key prerequisites for reliable modelling and monitoring of floods. However, for the hydrologists, it has been very difficult to simulate the flash floods over regions where rain gauge networks are not available or very sparse, particularly over complex topography or remote areas. With the availability of 
real-time and post-real-time satellite precipitation estimates, there are tremendous opportunities for the improvement of hydrological simulations and enhancement of flood forecasting capacity in medium to large river basins, exclusively in the less developed and remote areas [5-8]. Previously, many researchers have used satellite-based precipitation products for hydrological modelling, drought monitoring, prediction and monitoring of flash floods, and climate-related research because of their global coverage [9-15]. Several satellitebased precipitation products, utilizing thermal infrared (IR) and/or passive microwave (PMW) sensors for quantitative estimation of precipitation, are available for the research community. Among them, in order to estimate the precipitation at 3-hourly temporal and $0.25^{\circ} \times 0.25^{\circ}$ spatial resolution, the advantages of both IR and PWM sensing techniques are combined in the algorithm of Tropical Rainfall Measuring Mission (TRMM) Multisatellite Precipitation Analysis (TMPA). The upgraded version 7 (V7) of TMPA was released by the National Aeronautics and Space Administration (NASA) Goddard Earth Sciences Data and Information Services Centre (GESDISC) in May 2012. The real-time product, TMPA-3B42RT, was available in October 2012 while gauge adjusted post-real-time product, TMPA-3B42V7, was available in July 2012. These products are available for the period of 17 years (January 1998 to April 2015) and, after a gap of two years, they will continue to be produced through the mid of 2017. The instantaneous availability, high orientation, and calibration of satellite-based precipitation products exposed new horizons for researchers in the understanding and application of this information for regional and global hydrological applications.

Although satellite-based precipitation estimates are readily available, their reliability is still under question because space-based information is often influenced by the atmospheric and/or topographic effects and other technical factors [16]. Moreover, the use of satellite-based precipitation information for flood prediction and monitoring cannot be obtained without evaluating the performance of these estimates [17]. Several researchers have evaluated the performance of satellite-based precipitation products using rain gauge observations over complex topographic regions [18, 19]. Earlier, it was observed that it is essential to evaluate the performance of satellite-based precipitation products by using in situ rain gauge data before the application of these products with great confidence in a specific area [20]. In another study, the performance of satellite-based precipitation estimates over northwestern Europe, including TMPA3B42RT, has been evaluated [21]. They concluded that the precipitation magnitudes were substantially underestimated by using the satellite data over the most complex geography. In Chinese Mainland, the performance of four high-resolution satellite-based precipitation products including real-time and post-real-time version 7 TMPA products was evaluated by Qin et al. [22]. They reported that the post-real-time TMPA product overestimates the precipitation magnitudes while real-time TMPA estimates agreed well with the rain gauge observations. Prakash et al. [23] compared the satellite-based precipitation estimates of TMPA and Global Precipitation Management (GPM) with rain gauge observations to evaluate the performance of these products during heavy precipitation events. They reported that the TMPA products overestimate the heavy precipitation events as compared to GPM. Chen et al. [24] evaluated the performance of CMORPH and PERSIANN-CCS satellite-based precipitation products during an extreme storm event of July 21, 2012, over Beijing. They concluded that both satellite-based products underestimated the precipitation magnitudes and also both products failed to capture the temporal variation of storm precipitation. A few number of studies have reported the performance evaluation of upgraded TMPA products during extreme precipitation events. In this regard, Huang et al. [25] evaluated the performance of real-time and post-real-time TMPA products during the extreme precipitation event of July 2012 in Beijing and concluded that both latest TMPA products still had limitations. No particular study was carried out to evaluate the performance of the latest TMPA precipitation products during the extreme precipitation events over Hindukush mountainous region. Therefore, this study will fill the gap of this research. The purpose of this study is to evaluate the performance of real-time and post-real-time version 7 TMPA precipitation products for the extreme precipitation event of 28-30 July 2010 over Swat River Basin situated in the complex terrain mountainous region of Hindukush, Pakistan. This paper is organized as follows. In Section 2, case study specifications are described. Datasets and methods to analyse the characteristics and error quantification for the satellitebased precipitation estimates for the extreme event of 28-30 July 2010, (from 00:00 UTC 28 July to 00:00 UTC 31 July 2010) are described in Section 3. Section 4 presents the results and discussion, followed by concluding remarks in Section 5 .

\section{Case Study Specifications}

This study was conducted for a particular basin, Swat River Basin $\left(14039 \mathrm{~km}^{2}\right)$, nested within the complex topography of Hindukush Mountains. The study area lies in the northern region of Pakistan, ranging from $70^{\circ} 59^{\prime} \mathrm{E}$ to $72^{\circ} 47^{\prime} \mathrm{E}$ and from $34^{\circ} 20^{\prime} \mathrm{N}$ to $35^{\circ} 56^{\prime} \mathrm{N}$ (Figure 1). The highest altitude within the study area is 5,920 meters above mean sea level (henceforth $\mathrm{m}$ a.m.s.l.) and the lowest is $375 \mathrm{~m}$ a.m.s.l.; the average altitude is $2180 \mathrm{~m}$ a.s.l. Vegetation can be seen mostly between $1,800 \mathrm{~m}$ a.s.l. and 3,400 $\mathrm{m}$ a.s.l., and glaciers are visible above the altitude of 4,000 $\mathrm{m}$ a.s.l. Meteorology of the area suggests that the average annual precipitation over the entire basin ranges from $375 \mathrm{~mm}$ to $1,250 \mathrm{~mm}$. Precipitation is mostly concentrated in two seasons, winter (January to March) and summer (July to September), that is, westerlies and monsoon. Considerably high precipitation occurs during winter, but the intense flood generating precipitation events only occur during the summer monsoon season. It is an elevated basin and heavy isolated precipitation events in summer are often caused by the orographic lifting of the monsoon air mass arriving from the south to southeast direction [1]. In 2010, the flood in Swat River was experienced due to monsoon precipitation.

Swat River is very important for the economic development of this region. There are two hydroelectric power plants with a combined operative capacity of $123 \mathrm{MW}$ which 


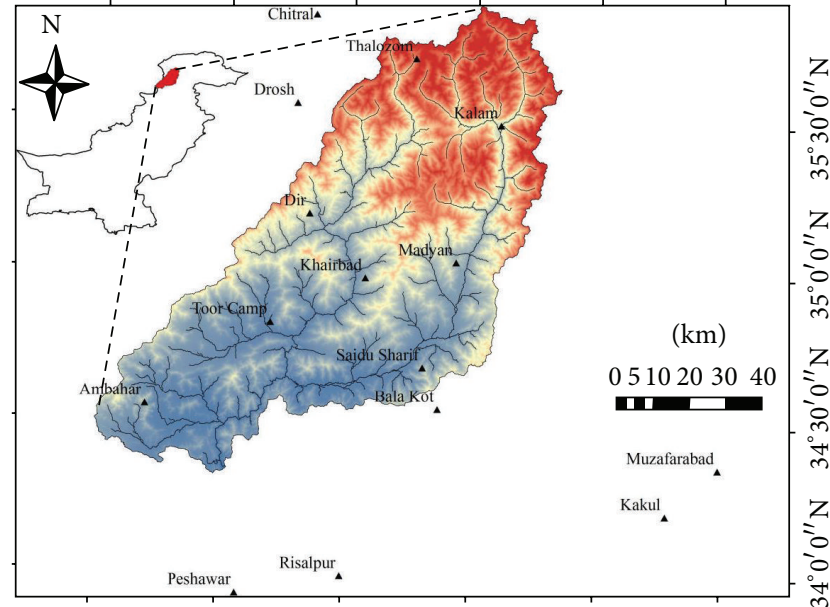

$71^{\circ} 0^{\prime} 0^{\prime \prime} \mathrm{E} 71^{\circ} 30^{\prime} 0^{\prime \prime} \mathrm{E} 72^{\circ} 0^{\prime} 0^{\prime \prime} \mathrm{E} 72^{\circ} 30^{\prime} 0^{\prime \prime} \mathrm{E} 73^{\circ} 0^{\prime} 0^{\prime \prime} \mathrm{E} 73^{\circ} 30^{\prime} 0^{\prime \prime} \mathrm{E}$

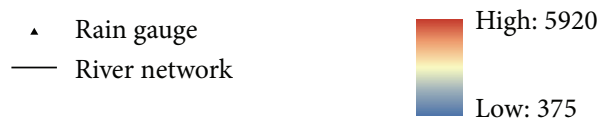

Figure 1: Physiographic features of Swat Basin and locations of rain gauge stations.

contribute to the National Grid System of the country. Another hydropower generation project, Mohmand Dam Hydropower Project with an estimated installed capacity of 740 megawatts (MW), is also proposed on this river. Mohmand Dam will be a multipurpose dam, accompanied by the hydroelectric power generation; it will irrigate 15,100 acres of agricultural land and will also protect Charsadda, Peshawar, and Nowshera districts from flash floods, which were severely affected by flooding in 2010 [26].

\section{Materials and Methods}

3.1. Precipitation Datasets. Catastrophic precipitation storm of 28-30 July 2010, in the northwestern region of Pakistan, was selected for quantitative evaluation of satellite-based precipitation estimates using available in situ rain gauge observations. In the present work, the rain gauge observations of 15 gauging stations (eight within and seven outside of the basin boundary) on three-hourly basis were obtained from Pakistan Meteorological Department (PMD) and Water and Power Development Authority (WAPDA). The real-time and post-real-time TMPA products, at fine resolution which is 3-hourly temporal and $0.25^{\circ} \times 0.25^{\circ}$ spatial, were obtained from open sourced repository at the website of Goddard Space Flight Centre. These products are freely available with quasi-global coverage $(50 \mathrm{~N}-\mathrm{S})$ to accommodate various needs for a wide range of applications [27].

3.2. Methods. The TMPA-based real-time and post-real-time precipitation estimates for the extreme storm event were compared with rain gauge observations at points (gauging station) and basin levels. The ArealRain Extension in ArcView GIS [28] was used to estimate the gauge-based basin average precipitation. As the locations of the centres of TMPA grid cells $\left(0.25^{\circ} \times 0.25^{\circ}\right.$ spatial resolution $)$ and the gauging stations do not coincide with each other, the inverse distance weightage method was used to estimate the 3-hourly satellite precipitation estimates at the locations of gauging stations. Previously, Arias-Hidalgo et al. [29] have used this method to estimate the TMPA estimates at the rain gauge locations. Satellite-based areal average precipitation has been produced from both satellite products by averaging all the pixels that lie within the study area. The performance of both TMPA precipitation products was evaluated by using continuous evaluation indexes (CEI) and categorical indexes (CI), where CEI was applied on both gauging station and whole basin scales accumulated precipitation estimates and CI was applied on precipitation time series at the basin scale. Areal-averaged precipitation over the basin was estimated from rain gauge measurements within and around the basin.

3.2.1. Continuous Evaluation Indexes. The performance of $3 \mathrm{~B} 42 \mathrm{RT}$ and $3 \mathrm{~B} 42 \mathrm{~V} 7$ precipitation products was evaluated by using five widely used continuous evaluation indexes. Among those indexes, Pearson's correlation coefficient (CC) was used to assess the scale of agreement between the rain gauge measurements and estimates of TMPA products. The mean error (ME) was selected to evaluate the average difference between satellite and gauge precipitation datasets; the mean absolute error (MAE) was used to find out the average magnitude of the error, while root mean square error (RMSE), which gives more importance to the larger errors as compared to mean absolute error, was used to find out the average error magnitude. Relative bias (BIAS) was calculated to describe the magnitude of the difference between the gauge and satellite estimates. CC and BIAS were dimensionless, while all other parameters were in millimetres $(\mathrm{mm})$. The respective formulas are given by

$$
\begin{aligned}
\mathrm{CC} & =\frac{\sum_{i=1}^{n}\left(G_{i}-\bar{G}\right)\left(S_{i}-\bar{S}\right)}{\sqrt{\sum_{i=1}^{n}\left(G_{i}-\bar{G}\right)^{2}} \times \sqrt{\sum_{i=1}^{n}\left(S_{i}-\bar{S}\right)^{2}}}, \\
\mathrm{ME} & =\frac{1}{n} \sum_{i=1}^{n}\left(S_{i}-G_{i}\right), \\
\mathrm{MAE} & =\frac{1}{n} \sum_{i=1}^{n}\left|S_{i}-G_{i}\right|, \\
\mathrm{RMSE} & =\sqrt{\frac{1}{n} \sum_{i=1}^{n}\left(S_{i}-G_{i}\right)^{2},} \\
\mathrm{BIAS} & =\frac{\sum_{i=1}^{n}\left(S_{i}-G_{i}\right)}{\sum_{i=1}^{n} G_{i}} \times 100,
\end{aligned}
$$

where $n$ is the total number of pairs of satellite and gauge data; $S_{i}$ and $G_{i}$ are the $i$ th value of satellite and gauge precipitations data, respectively; and $\bar{S}$ and $\bar{G}$ are the mean values of satellite and gauge data, respectively. 

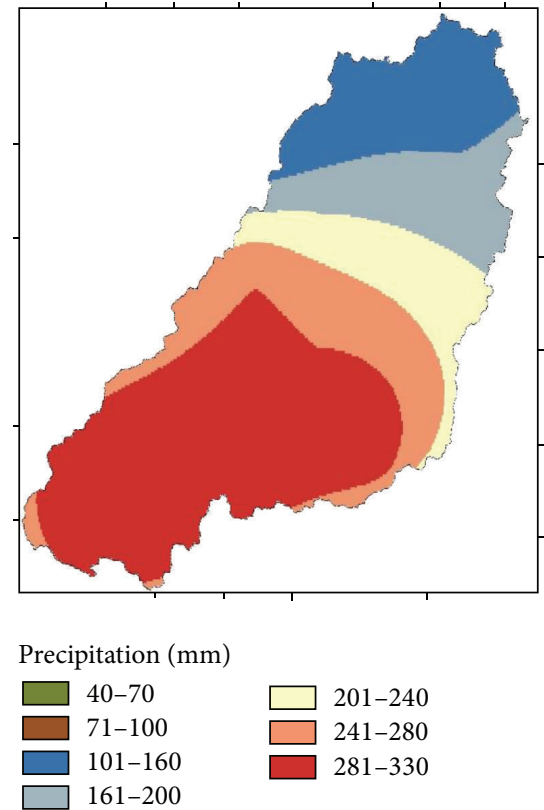

(a)
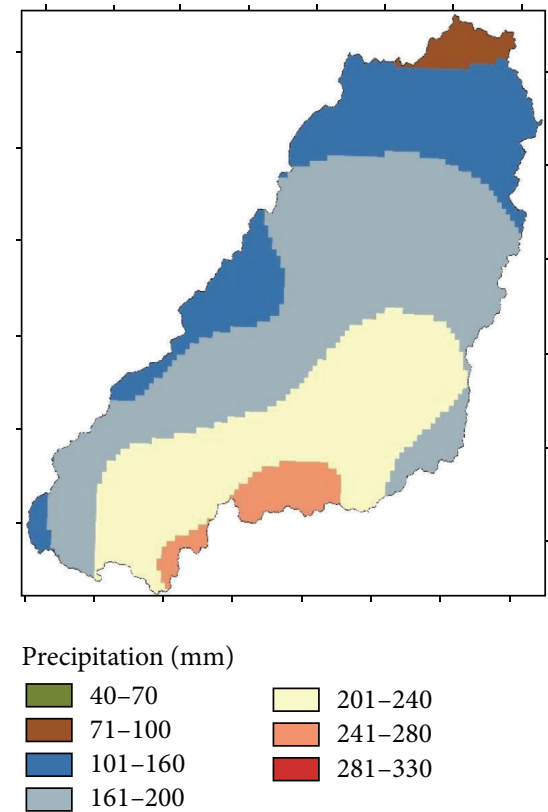

$161-200$
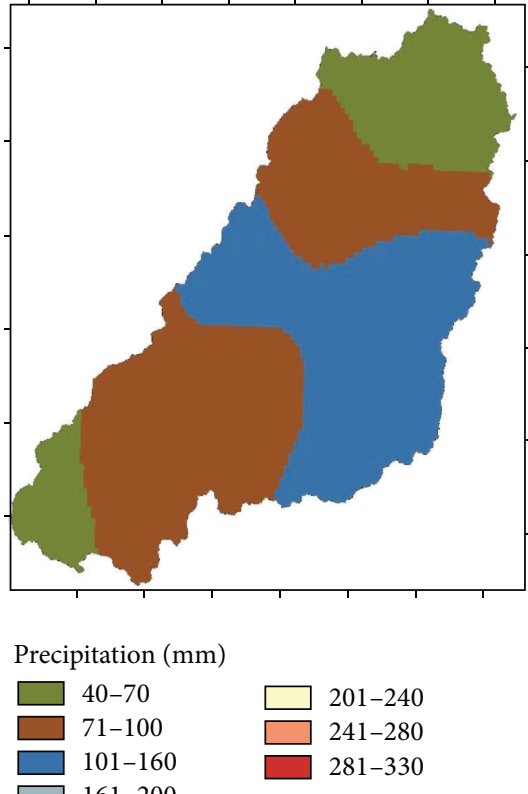

(c)

FIGURE 2: Kriging interpolation of (a) gauge, (b) 3B42V7, and (c) 3B42RT accumulated precipitation estimates, respectively.

3.2.2. Categorical Indexes. For more precise evaluations of the precipitation time series of TMPA products, three categorical statistical indexes, including the false alarm ratio (FAR), probability of detection (POD), and critical success index (CSI), were calculated to measure the correspondence between the satellite observations and gauge data. POD represents how often the precipitation occurrences are correctly detected by satellite. The FAR denotes the fraction of cases in which the satellite detects the precipitation when actually there is no precipitation. CSI shows the overall fraction of gauge and/or satellite precipitation events that were correctly predicted. No precipitation or precipitation events were identified by the values of precipitation thresholds. The perfect value of FAR was 0 but 1 for each of POD and CSI and their respective formulas are given as follows:

$$
\begin{aligned}
\mathrm{FAR} & =\frac{T_{F}}{T_{H}+T_{F}}, \\
\mathrm{POD} & =\frac{T_{H}}{T_{H}+T_{M}}, \\
\mathrm{CSI} & =\frac{T_{H}}{T_{H}+T_{M}+T_{F}},
\end{aligned}
$$

where $H$ represents the observed precipitation correctly detected; $M$ is the observed precipitation not detected; $F$ is the precipitation detected but not observed; and $T_{H}, T_{M}$, and $T_{F}$ are the times of occurrence of the corresponding case.

\section{Results and Discussions}

4.1. Evaluation of Accumulated Precipitation. Figure 2 shows the three-hourly rain gauge observations and satellite-based precipitation estimates that were accumulated from 00:00 AM on 28 July to $00: 0031$ July 2010 to yield storm total precipitation. Kriging interpolation technique was applied to interpolate the accumulated precipitation over the study domain. The interpolated results of gauge accumulated precipitation (Figure 2(a)) show that the heavy precipitation extends from the north to the south of Swat Basin. $3 \mathrm{~B} 42 \mathrm{~V} 7$ captures the intense precipitation that extends from northwest to southeast direction (Figure 2(b)) but generally tried to match spatial pattern of the observed precipitation. 3B42RT misplaced the intense storm extending and showed the extents of most intense precipitation in the middle parts with an increase towards the western region of the study area. Both TMPA products underestimated the precipitation by a wide margin, with maximum precipitation less than $250 \mathrm{~mm}$ estimated by 3B42V7 and less than $130 \mathrm{~mm}$ captured by 3B42RT.

Comparison of the accumulated precipitation on station and basin levels is shown in Figure 3. 3B42RT significantly underestimated the precipitation at all gauging stations and also at basin scale, while 3B42V7 overestimated the storm precipitation at two gauging stations (Chitral and Drosh) and underestimated it at all other gauging stations and basin level. Quantitative comparisons of areal average precipitation on the basin scale show that $3 \mathrm{~B} 42 \mathrm{~V} 7$ has a good correlation $(\mathrm{CC}=0.87)$, but $3 \mathrm{~B} 42 \mathrm{RT}$ has a very low correlation (CC $=0.20)$ with gauge-based areal-averaged precipitation; it is evident that 3B42RT cannot capture well the spatial pattern of precipitation in the study area. Statistical errors (ME, MAE, and RMSE) are high in 3B42RT as compared to 3B42V7 (as shown in Figure 4). Both TMPA products show significant underestimation ( $32.15 \%$ by $3 \mathrm{~B} 42 \mathrm{~V} 7$ and $66.73 \%$ by $3 \mathrm{~B} 42 \mathrm{RT}$ ) as compared to gauge observed accumulated precipitation. 


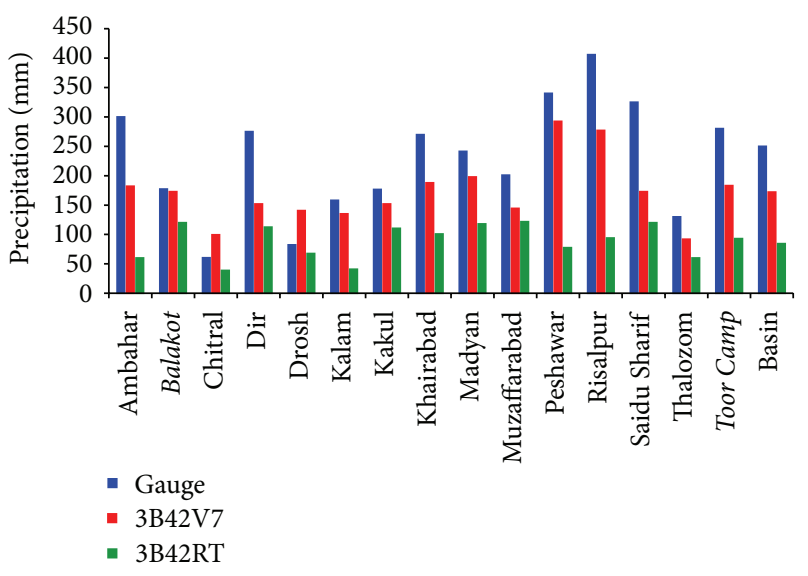

FIGURE 3: Station-based gauge and 3B42V7/3B42RT three-day accumulated precipitation.

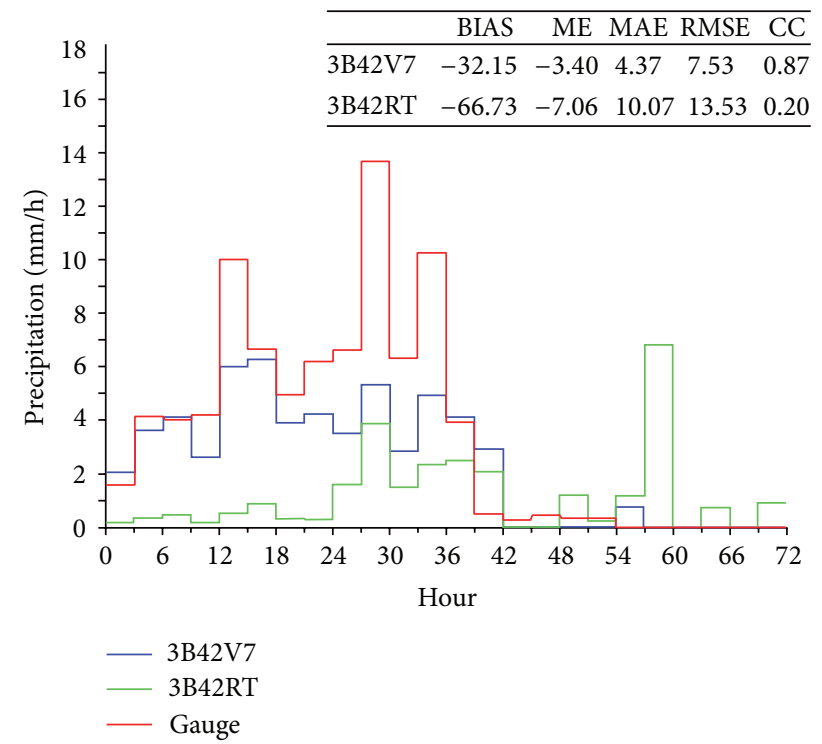

FIgure 4: Precipitation time series over Swat Basin during 28-30 July 2010 storm event.

However, the overall performance of 3B42V7 was better than 3B42RT in order to capture the spatial pattern of precipitation in the study area.

Point-based quantitative comparisons between both satellite precipitation products and gauge-based observations are shown in Table 1. Results showed that $3 \mathrm{~B} 42 \mathrm{~V} 7$ has good CC (best value of 0.95 at Peshawar) with gaugebased observations, whereas 3B42RT has low CC (best value of 0.53 at Dir). These CC values show that $3 \mathrm{~B} 42 \mathrm{~V} 7$ has generally followed the spatial pattern of precipitation during the extreme storm event, but 3B42RT failed to capture the spatial variation of precipitation in the entire study area. The values of BIAS show that both TMPA products, 3B42V7 and 3B42RT, significantly underestimated the storm accumulated precipitation at all gauging stations except Chitral and Drosh gauging stations, where $3 \mathrm{~B} 42 \mathrm{~V} 7$ overestimated the precipitation (estimated best values of BIAS for 3B42V7 are $-2.6 \%$

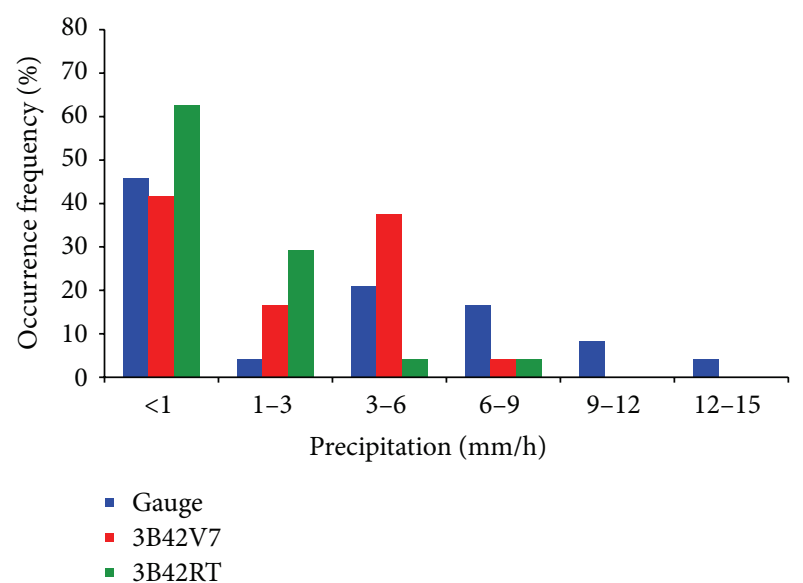

FIGURE 5: Occurrence frequencies of gauge, 3B42V7, and 3B42RT for areal-averaged precipitation.

at Bala Kot and for $3 \mathrm{~B} 42 \mathrm{RT}$ are $-17.9 \%$ at Drosh gauging station).

4.2. Evaluation of Precipitation Time Series. The ability to capture the accurate temporal variation of precipitation is the most important thing for monitoring of flash floods and landslides. Figure 4 presents the time series plots of arealaveraged gauge and satellite-based precipitation estimates, accumulated on the hourly basis in the Swat Basin. The gauge observed precipitation showed that the peak of the $72 \mathrm{hr}$ storm event occurred at the 27th hour and after the 36th hour it decreased dramatically and became less than $1 \mathrm{~mm} / \mathrm{h}$ by the 39th hour. The 3B42V7-based precipitation generally increased from the first hour to the peak occurring at the 15th hour and then showed a mix of increasing and decreasing trend up to the 42 nd hour after that it decreased suddenly to less than $0.5 \mathrm{~mm} / \mathrm{h}$ by the 45 th hour. 3B42RT produced the peak of precipitation at the 57th hour and substantially underestimated the precipitation magnitudes throughout the event. Both satellite-based products failed to capture the peak and temporal variation of precipitation. Both TMPA products underestimate the precipitation rates throughout the storm event.

It was noticed that the gauge observed very heavy precipitation rate in the study area $(>13 \mathrm{~mm} / \mathrm{h})$ which lasted for three hours. Hong et al. [30] fixed a limit of precipitation intensityduration threshold for landslides which is $12.45 \mathrm{~mm} / \mathrm{h}$ for 0.42-hour duration. Both of the satellite-based precipitation products did not exceed the minimum bound of $12.45 \mathrm{~mm} / \mathrm{hr}$. This means that if the precipitation estimates of 3B42V7 and $3 \mathrm{~B} 42 \mathrm{RT}$ are used as an input data to the landslide models, then these datasets might not be able to trigger the debris and landslides.

Figure 5 shows the frequency distribution of hourly precipitation for different precipitation intensities for the arealaveraged precipitation time series. Results show that 3B42V7 slightly underestimates the low-intensity precipitation (less than $1 \mathrm{~mm} / \mathrm{h}$ ), while up to $3 \mathrm{~mm} / \mathrm{h}$ precipitation intensities were overestimated by 3B42RT. Precipitation intensities 
TABLE 1: Statistics of satellite precipitation products for 28-30 July 2010 precipitation.

\begin{tabular}{lccccccccccc}
\hline \multirow{2}{*}{ Station name } & Elevation & & & $3 \mathrm{~B} 42 \mathrm{~V} 7$ & & & & \multicolumn{3}{c}{ 3B42RT } \\
& $\mathrm{m}$ & $\mathrm{CC}$ & $\mathrm{ME}$ & MAE & RMSE & BIAS & CC & ME & MAE & RMSE & BIAS \\
\hline Balakot & 995 & 0.88 & -0.2 & 2.6 & 4.8 & -2.6 & -0.13 & -2.4 & 9.5 & 17.1 & -32.3 \\
Chitral & 1498 & 0.75 & 0.7 & 1.7 & 2.6 & 29.7 & 0.26 & -0.9 & 2.5 & 3.4 & -35.5 \\
Dir & 1375 & 0.77 & -5.1 & 7.5 & 13.3 & -44.7 & 0.53 & -6.8 & 9.6 & 16.1 & -59.1 \\
Drosh & 1465 & 0.76 & 1.4 & 2.3 & 3.8 & 41.5 & 0.12 & -0.6 & 3.4 & 5.4 & -17.9 \\
Kakul & 1308 & 0.94 & -1.0 & 2.4 & 4.1 & -13.7 & -0.06 & -2.7 & 10.6 & 22.9 & -37.3 \\
Kalam & 2103 & 0.76 & -0.9 & 4.2 & 6.2 & -14.3 & 0.25 & -5.2 & 5.8 & 10.4 & -79.3 \\
Muzaffarabad & 702 & 0.53 & -2.4 & 5.6 & 10.7 & -28.2 & 0.07 & -3.3 & 11.0 & 22.9 & -39.4 \\
Peshawar & 360 & 0.95 & -2.0 & 3.8 & 6.2 & -14.0 & 0.01 & -10.9 & 14.3 & 21.9 & -77.2 \\
Risalpur & 317 & 0.78 & -4.6 & 13.5 & 17.4 & -27.4 & 0.15 & -13.0 & 16.5 & 25.9 & -76.8 \\
Saidu Sharif & 961 & 0.76 & -6.2 & 7.6 & 12.0 & -46.1 & -0.08 & -8.3 & 14.8 & 22.0 & -61.5 \\
Madyan & 1320 & 0.78 & -1.3 & 4.6 & 7.3 & -12.5 & -0.08 & -4.9 & 11.3 & 18.2 & -49.2 \\
Khairabad & 894 & 0.69 & -3.4 & 6.0 & 9.4 & -30.4 & 0.28 & -7.0 & 9.6 & 14.0 & -62.6 \\
Toor Camp & 854 & 0.70 & -4.0 & 6.6 & 11.5 & -34.6 & 0.13 & -7.8 & 10.6 & 17.2 & -66.8 \\
Thalozom & 4200 & 0.69 & -1.6 & 4.0 & 5.8 & -29.2 & 0.25 & -2.9 & 5.1 & 8.4 & -53.8 \\
Ambahar & 694 & 0.72 & -4.9 & 8.1 & 12.2 & -39.3 & 0.48 & -10.0 & 10.8 & 17.7 & -80.0 \\
\hline
\end{tabular}
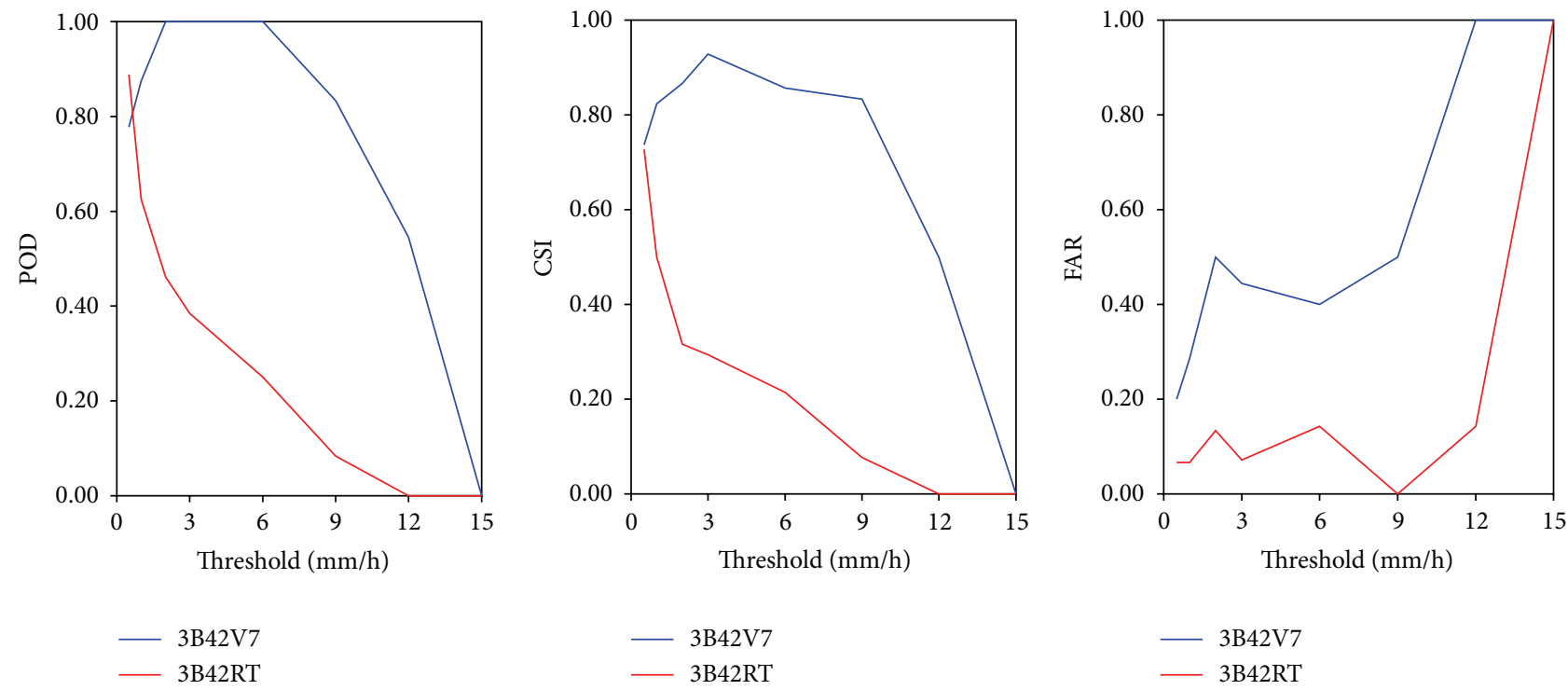

FIGURE 6: Categorical statistics of 3B42V7 and 3B42RT for POD, CSI, and FAR.

between 1 and $6 \mathrm{~mm} / \mathrm{h}$ were overestimated by 3B42V7, while 3 to $9 \mathrm{~mm} / \mathrm{h}$ intensities were underestimated by 3B42RT. Both satellite products failed to capture the precipitation above $9 \mathrm{~mm} / \mathrm{h}$.

Categorical statistics provides an insight into the performance of the probability of detection, critical success index, and false alarm rate. Figure 6 exhibits that 3B42V7 has maximum (100\%) probability of detection for precipitation intensities between 2 and $6 \mathrm{~mm} / \mathrm{h}$ and it decreases rapidly with the increase of precipitation intensity. Similarly, CSI score of $3 \mathrm{~B} 42 \mathrm{~V} 7$ is high up to $9 \mathrm{~mm} / \mathrm{h}$ precipitation rate and becomes zero when the precipitation rate is more than $14 \mathrm{~mm} / \mathrm{h}$. The $3 \mathrm{~B} 42 \mathrm{RT}$ has the high probability of detection
( $>80 \%$ ) for low precipitation rates $(<1 \mathrm{~mm} / \mathrm{hr})$, but it starts decreasing dramatically with the increase of precipitation intensity and becomes zero when the precipitation rate is more than $12 \mathrm{~mm} / \mathrm{h}$. Results of contingency statistics revealed that 3B42V7 and 3B42RT had very poor performance in order to capture the heavy precipitation rates. Similar results were also observed by the frequency distributions analysis shown in Figure 5.

The poor performance of both TMPA-based products is, maybe, due to the complex topography and associated orographic precipitation process in this region. The algorithms, based on IR, use the threshold values of cloud top temperature for precipitation estimation, but this temperature is 
too cold in case of orographic clouds which consequently cause the underestimation of orographic precipitations. The scattering of passive microwaves by ice aloft leads to the underestimation of precipitation in PM algorithms. Therefore, IR and PM algorithms used in the satellite-based products resulted in the underestimation of precipitation during the extreme storm event in this region.

\section{Summary and Conclusions}

The aim of this study was to evaluate the performance of the widely used TMPA products, 3B42RT and 3B42V7, during an extreme heavy precipitation event over Swat River Basin and adjacent areas in Hindukush Mountains. The observations of automatic rain gauge stations used a ground truth for the evaluation of TMPA products. Several graphical and statistical techniques have been employed in conjunction to evaluate the satellite-based products in terms of accumulated, time series precipitation, occurrence frequency, and contingency metrics. The results of this study are summarized as follows.

(a) 3B42RT failed to capture the spatial pattern of precipitation ( $\mathrm{CC}<0.25)$, but 3B42V7 had generally captured the precipitation spatial pattern $(\mathrm{CC}>0.80)$.

(b) Both TMPA products failed to follow the temporal variation of observed precipitation.

(c) 3B42V7 underestimated the areal-averaged precipitation by more than $32.15 \%$ and 3B42RT underestimated it by $66.73 \%$.

(d) 3B42V7 and 3B42RT are unable to detect intense precipitation rates (e.g., $>15 \mathrm{~mm} / \mathrm{h}$ ).

Both TMPA products, 3B42V7 and 3B42RT, revealed poor performance during extreme precipitation event in this region. The underestimation of accumulated storm precipitation by both TMPA products was mainly ascribed to complex topography and the orographic effect in this region. The results of this study are consistent with the findings of Huang et al. [25]. These two satellite-based precipitation products have limitations in terms of resolution and accuracy, particularly for such type of heavy precipitation events. Therefore, cautionary measures should be taken while 3B42V7 and 3B42RT are to be applied for hydrological modelling and monitoring of floods and landslides during heavy precipitation events. These findings will also be useful for algorithm developers of Global Precipitation Measuring Mission that was launched in 2014 with more advanced dualfrequency radar on board to provide better spatiotemporal coverage of satellite-based precipitation over the globe.

\section{Competing Interests}

The authors declare that there are no competing interests.

\section{Acknowledgments}

The present study was carried under the umbrella of Chinese Academy of Sciences and The World Academy of Sciences (CAS-TWAS) President's Fellowship Program at Cold and
Arid Regions Environmental and Engineering Research Institute. The work was also supported by the Ministry of Science and Technology of the People's Republic of China (Grant no. 2013CBA01808) and the National Natural Science Foundation of China (Grant nos. 41271082 and 41130638). The authors are grateful to the PMD and WAPDA for providing the data. The authors also graciously acknowledge the agencies who have voluntarily offered data online for research facilitation.

\section{References}

[1] WAPDA, Annual Flood Report 2010, Federal Flood Commission, Ministry of Water and Power, Islamabad, Pakistan, 2011.

[2] R. A. Houze Jr., K. L. Rasmussen, S. Medina, S. R. Brodzik, and U. Romatschke, "Anomalous atmospheric events leading to the summer 2010 floods in Pakistan," Bulletin of the American Meteorological Society, vol. 92, no. 3, pp. 291-298, 2011.

[3] S.-Y. Wang, R. E. Davies, W.-R. Huang, and R. R. Gillies, "Pakistan's two-stage monsoon and links with the recent climate change," Journal of Geophysical Research: Atmospheres, vol. 116, no. 16, Article ID D16114, 2011.

[4] P. J. Webster, V. E. Toma, and H.-M. Kim, "Were the 2010 Pakistan floods predictable?" Geophysical Research Letters, vol. 38, no. 4, Article ID L04806, 2011.

[5] M. M. Bitew and M. Gebremichael, "Evaluation of satellite rainfall products through hydrologic simulation in a fully distributed hydrologic model," Water Resources Research, vol. 47, no. 6, Article ID W06526, 2011.

[6] W. Wang, Q. Shao, S. Peng et al., "Reference evapotranspiration change and the causes across the Yellow River Basin during 1957-2008 and their spatial and seasonal differences," Water Resources Research, vol. 48, no. 5, Article ID W05530, 2012.

[7] X. Xue, Y. Hong, A. S. Limaye et al., "Statistical and hydrological evaluation of TRMM-based Multi-satellite precipitation analysis over the Wangchu Basin of Bhutan: are the latest satellite precipitation products $3 \mathrm{~B} 42 \mathrm{~V} 7$ ready for use in ungauged basins?" Journal of Hydrology, vol. 499, pp. 91-99, 2013.

[8] B. Yong, L. Ren, Y. Hong et al., "Spatial-temporal changes of water resources in a typical semiarid basin of North China over the past 50 years and assessment of possible natural and socioeconomic causes," Journal of Hydrometeorology, vol. 14, no. 4, pp. 1009-1034, 2013.

[9] J. Wang, Y. Hong, L. Li et al., "The coupled routing and excess storage (CREST) distributed hydrological model," Hydrological Sciences Journal, vol. 56, no. 1, pp. 84-98, 2011.

[10] C. Toté, D. Patricio, H. Boogaard, R. van der Wijngaart, E. Tarnavsky, and C. Funk, "Evaluation of satellite rainfall estimates for drought and flood monitoring in mozambique," Remote Sensing, vol. 7, no. 2, pp. 1758-1776, 2015.

[11] A. Milewski, R. Elkadiri, and M. Durham, "Assessment and comparison of TMPA satellite precipitation products in varying climatic and topographic regimes in Morocco," Remote Sensing, vol. 7, no. 5, pp. 5697-5717, 2015.

[12] J. Liu, Z. Duan, J. Jiang, and A. Zhu, "Evaluation of three satellite precipitation products TRMM 3B42, CMORPH, and PERSIANN over a subtropical Watershed in China," Advances in Meteorology, vol. 2015, 13 pages, 2015.

[13] M. Tan, A. Ibrahim, Z. Duan, A. Cracknell, and V. Chaplot, "Evaluation of six high-resolution satellite and ground-based 
precipitation products over Malaysia," Remote Sensing, vol. 7, no. 2, pp. 1504-1528, 2015.

[14] S. Prakash, A. K. Mitra, I. M. Momin, D. S. Pai, E. N. Rajagopal, and S. Basu, "Comparison of TMPA-3B42 versions 6 and 7 precipitation products with gauge-based data over India for the southwest monsoon period," Journal of Hydrometeorology, vol. 16, no. 1, pp. 346-362, 2015.

[15] L. Li, C. S. Ngongondo, C.-Y. Xu, and L. Gong, "Comparison of the global TRMM and WFD precipitation datasets in driving a large-scale hydrological model in southern Africa," Hydrology Research, vol. 44, no. 5, pp. 770-788, 2012.

[16] L. Tang and F. Hossain, "Investigating the similarity of satellite rainfall error metrics as a function of Köppen climate classification," Atmospheric Research, vol. 104-105, pp. 182-192, 2012.

[17] S. I. Khan, Y. Hong, J. J. Gourley, M. U. K. Khattak, B. Yong, and H. J. Vergara, "Evaluation of three high-resolution satellite precipitation estimates: potential for monsoon monitoring over Pakistan," Advances in Space Research, vol. 54, no. 4, pp. 670684, 2014.

[18] T. Dinku, S. Chidzambwa, P. Ceccato, S. J. Connor, and C. F. Ropelewski, "Validation of high-resolution satellite rainfall products over complex terrain," International Journal of Remote Sensing, vol. 29, no. 14, pp. 4097-4110, 2008.

[19] S.-H. Jiang, L.-L. Ren, B. Yong, X.-L. Yang, and L. Shi, "Evaluation of high-resolution satellite precipitation products with surface rain gauge observations from Laohahe Basin in northern China," Water Science and Engineering, vol. 3, no. 4, pp. 405417, 2010.

[20] S. Prakash and R. M. Gairola, "Validation of TRMM-3B42 precipitation product over the tropical Indian Ocean using rain gauge data from the RAMA buoy array," Theoretical and Applied Climatology, vol. 115, no. 3, pp. 451-460, 2014.

[21] C. Kidd, P. Bauer, J. Turk et al., "Intercomparison of highresolution precipitation products over northwest Europe," Journal of Hydrometeorology, vol. 13, no. 1, pp. 67-83, 2012.

[22] Y. Qin, Z. Chen, Y. Shen, S. Zhang, and R. Shi, "Evaluation of satellite rainfall estimates over the Chinese Mainland," Remote Sensing, vol. 6, no. 11, pp. 11649-11672, 2014.

[23] S. Prakash, A. K. Mitra, D. S. Pai, and A. AghaKouchak, "From TRMM to GPM: how well can heavy rainfall be detected from space?" Advances in Water Resources, vol. 88, pp. 1-7, 2016.

[24] S. Chen, H. Liu, Y. You et al., "Evaluation of high-resolution precipitation estimates from satellites during July 2012 Beijing flood event using dense rain gauge observations," PLoS ONE, vol. 9, no. 4, Article ID e89681, 2014.

[25] Y. Huang, S. Chen, Q. Cao et al., "Evaluation of version-7 TRMM multi-satellite precipitation analysis product during the Beijing extreme heavy rainfall event of 21 July 2012," Water, vol. 6, no. 1, pp. 32-44, 2014.

[26] I. Ahmad, D. Tang, T. F. Wang, M. Wang, and B. Wagan, "Precipitation trends over time using Mann-Kendall and Spearman's rho tests in Swat River Basin, Pakistan," Advances in Meteorology, vol. 2015, Article ID 431860, 15 pages, 2015.

[27] G. J. Huffman, R. F. Adler, D. T. Bolvin et al., "The TRMM multisatellite precipitation analysis (TMPA): quasi-global, multiyear, combined-sensor precipitation estimates at fine scales," Journal of Hydrometeorology, vol. 8, no. 1, pp. 38-55, 2007.

[28] I. Petras, "AreaRain.ave Areal Precipitation Calculation using Thiessen Polygons," AS11813.zip, 2001.

[29] M. Arias-Hidalgo, B. Bhattacharya, A. E. Mynett, and A. van Griensven, "Experiences in using the TMPA-3B42R satellite data to complement rain gauge measurements in the Ecuadorian coastal foothills," Hydrology and Earth System Sciences, vol. 17, no. 7, pp. 2905-2915, 2013.

[30] Y. Hong, R. F. Adler, A. Negri, and G. J. Huffman, "Flood and landslide applications of near real-time satellite rainfall products," Natural Hazards, vol. 43, no. 2, pp. 285-294, 2007. 

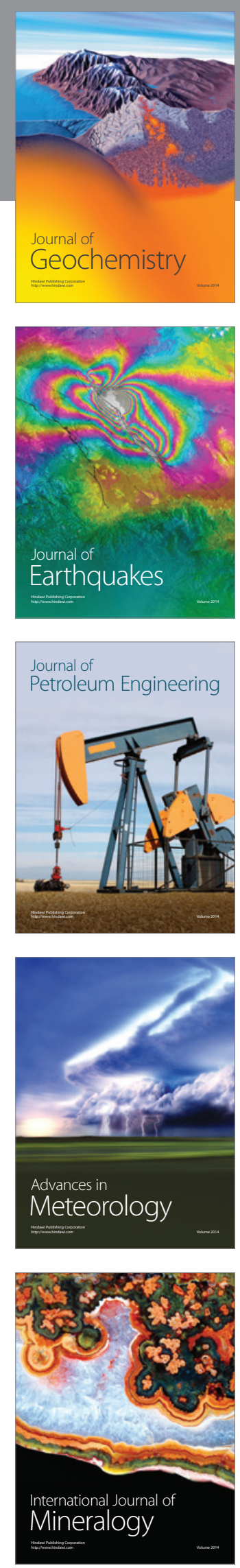
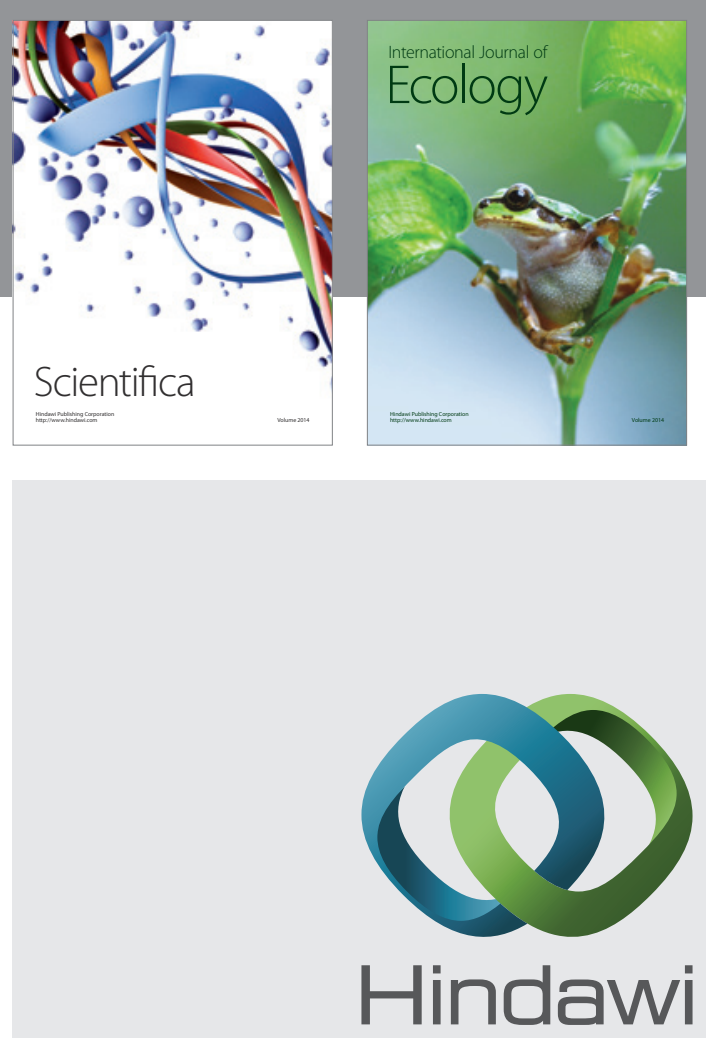

Submit your manuscripts at

http://www.hindawi.com
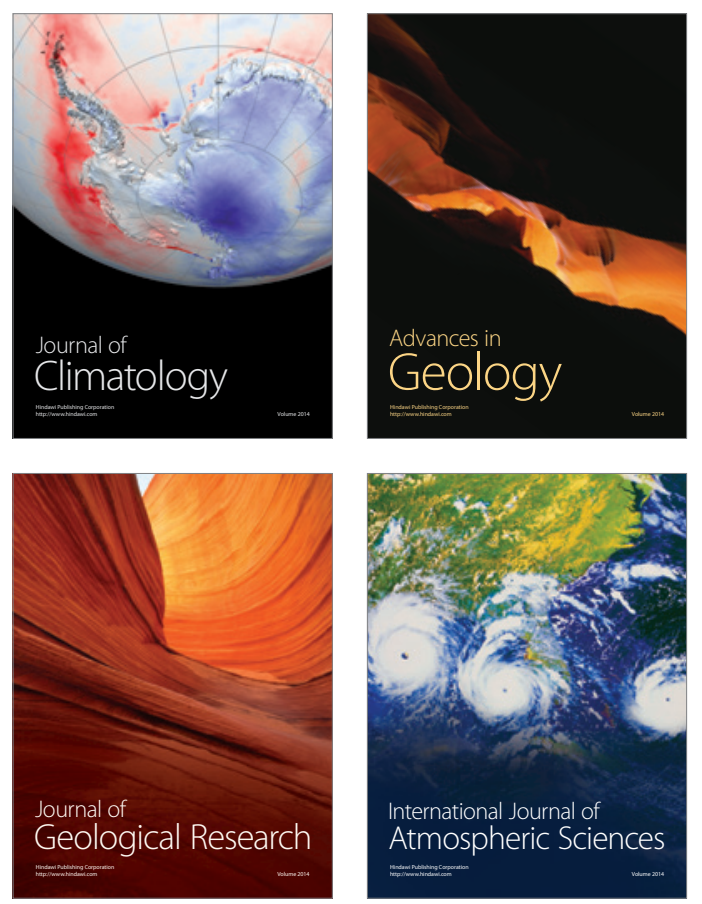

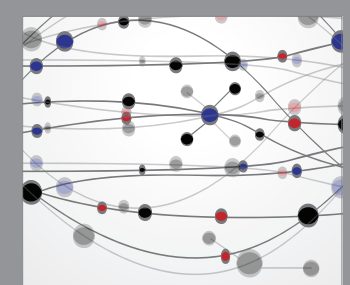

The Scientific

\section{World Journal}
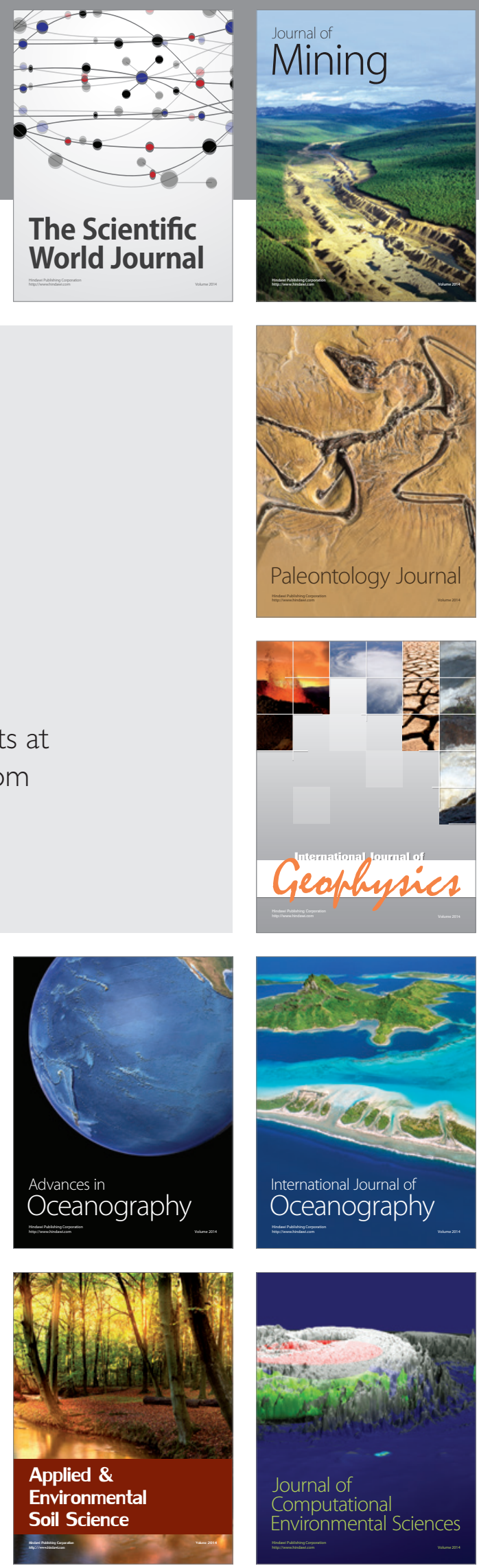